Eng, Marty L. and Welty, Timothy E. (1999) Management of Hallucinations and Psychosis in Parkinson's Disease. Am J Geriat Pharm. 8(4), 316-330. PMID: 20869621. Publisher's official version: <http://dx.doi.org/10.1016/j.amjopharm.2010.08.004> . Open Access version: http://kuscholarworks.ku.edu/dspace/.

[This document contains the author's accepted manuscript. For the publisher's version, see the link in the header of this document.]

Paper citation: Eng, Marty L. and Welty, Timothy E. (1999) Management of Hallucinations and Psychosis in Parkinson's Disease. Am J Geriat Pharm. 8(4), 316-330. PMID: 20869621

\author{
Keywords: \\ Parkinson's disease \\ hallucinosis \\ hallucinations \\ psychosis \\ atypical antipsychotics \\ neuroleptics
}

\begin{abstract}
:
BACKGROUND: Hallucinations and psychosis are common in patients with Parkinson's disease (PD), with reported prevalences of up to $48 \%$ and $80 \%$, respectively. However, few randomized, double-blind, placebo-controlled trials evaluating the treatment options have appeared in the literature. The studies that have been published were complicated by lack of agreement on the diagnosis of psychosis in PD, poor completion rates, mixed populations that included dementia, and other issues. Several reviews, guidelines, and consensus statements have sought to establish standards for treating these symptoms of PD. In 2006, the American Academy of Neurology (AAN) published a practice guideline (based on articles published up to 2004) for management of depression, psychosis, and dementia in patients with PD. Since then, a number of relevant studies have been published. OBJECTIVE: The purpose of this article was to review data that have appeared in the literature since publication of the AAN guideline regarding the management of hallucinations and psychosis in PD. METHODS: A literature search of the PubMed, CINAHL, and Psychlnfo databases was conducted for human studies published in English from January 2004 to June 2010. All clinical studies were included except case reports and case series. Studies with $<20$ participants were also excluded. Search terms included psychosis, hallucinosis, hallucination, delusion, Parkinson, atypical antipsychotic, neuroleptic, aripiprazole, clozapine, olanzapine, quetiapine, risperidone, and ziprasidone. RESULTS: Thirteen studies were included in the review: 3 studies of clozapine, 7 studies of quetiapine, 2 head-to-head trials comparing quetiapine and clozapine, and 1 noncomparative trial of clozapine or quetiapine interventions. Most of the studies included participants with a mean age in the early to mid 70 s and a mean duration of PD typically > 10 years. CONCLUSIONS: Results of the identified studies suggested that patients with PD might benefit from long-term clozapine therapy. Results of the quetiapine studies were conflicting. However, no statistically significant difference in effectiveness was found between quetiapine and clozapine in comparative trials. The significance of the differences in treatment responses between patients with dementia and those without dementia remains unclear, and it was not possible to draw conclusions for or against other atypical antipsychotics because of insufficient evidence. Further studies are needed to address the methodologic issues in the current trials and to assess safety issues in larger cohorts.
\end{abstract}




\title{
Management of Hallucinations and Psychosis in Parkinson's Disease
}

\author{
Marty L. Eng, PharmD; and Timothy E. Welty, MA, PharmD \\ Department of Pharmacy Practice, University of Kansas School of Pharmacy, Kansas City, Kansas
}

\begin{abstract}
Background: Hallucinations and psychosis are common in patients with Parkinson's disease (PD), with reported prevalences of up to $48 \%$ and $80 \%$, respectively. However, few randomized, double-blind, placebo controlled trials evaluating the treatment options have appeared in the literature. The studies that have been published were complicated by lack of agreement on the diagnosis of psychosis in PD, poor completion rates, mixed populations that included dementia, and other issues. Several reviews, guidelines, and consensus statements have sought to establish standards for treating these symptoms of PD. In 2006, the American Academy of Neurology (AAN) published a practice guideline (based on articles published up to 2004) for management of depression, psychosis, and dementia in patients with PD. Since then, a number of relevant studies have been published.

Objective: The purpose of this article was to review data that have appeared in the literature since publication of the AAN guideline regarding the management of hallucinations and psychosis in PD.

Methods: A literature search of the PubMed, CINAHL, and PsychInfo databases was conducted for human studies published in English from January 2004 to June 2010. All clinical studies were included except case reports and case series. Studies with $<20$ participants were also excluded. Search terms included psychosis, hallucinosis, hallucination, delusion, Parkinson, atypical antipsychotic, neuroleptic, aripiprazole, clozapine, olanzapine, quetiapine, risperidone, and ziprasidone.

Results: Thirteen studies were included in the review: 3 studies of clozapine, 7 studies of quetiapine, 2 head-tohead trials comparing quetiapine and clozapine, and 1 noncomparative trial of clozapine or quetiapine interventions. Most of the studies included participants with a mean age in the early to mid 70 s and a mean duration of PD typically $>10$ years.

Conclusions: Results of the identified studies suggested that patients with PD might benefit from long-term clozapine therapy. Results of the quetiapine studies were conflicting. However, no statistically significant difference in effectiveness was found between quetiapine and clozapine in comparative trials. The significance of the differences in treatment responses between patients with dementia and those without dementia remains unclear, and it was not possible to draw conclusions for or against other atypical antipsychotics because of insufficient evidence. Further studies are needed to address the methodologic issues in the current trials and to assess safety issues in larger cohorts. (Am J Geriatr Pharmacother. 2010;8:XXX-XXX) (C) 2010 Excerpta Medica Inc.
\end{abstract}

Key words: Parkinson's disease, hallucinosis, hallucinations, psychosis, atypical antipsychotics, neuroleptics. 
Eng, Marty L. and Welty, Timothy E. (1999) Management of Hallucinations and Psychosis in Parkinson's Disease.

Am J Geriat Pharm. 8(4), 316-330. PMID: 20869621. Publisher's official version: <http://dx.doi.org/10.1016/j.amjopharm.2010.08.004> .

Open Access version: http://kuscholarworks.ku.edu/dspace/.

\section{INTRODUCTION}

Psychotic symptoms such as hallucinations and delusions are common in patients with Parkinson's disease (PD). The estimated prevalence of hallucinations ranges from $\sim 10 \%$ to $48 \%$, and the prevalence of delusions ranges from $3 \%$ to $80 \%{ }^{1-9}$ Risk factors for the development of psychotic symptoms include cognitive impairment, dementia, age $>65$ years, advanced disease $(>6$ years' duration), advanced PD (Unified Parkinson Disease Rating Scale [UPDRS] score >44.5), presence of sleep disorders, concomitant depression, ocular dysfunction, family history of dementia, use of dopamine agonists, and axial parkinsonism..$^{10-13}$

Recently, Ravina et $\mathrm{al}^{14}$ developed diagnostic criteria for psychosis in PD. The characteristic symptoms include $\geq 1$ of the following: illusions, false sense of presence, hallucinations, and delusions. The clinical definition of psychosis in PD also must include a primary diagnosis of PD using the UK Brain Bank Criteria, and the onset of symptoms must occur after the diagnosis of PD. In addition, psychotic symptoms must be recurrent or continuous for $\geq 1$ month. These criteria rule out delirium and brief psychotic disorders. Associated features (eg, insight, dementia, PD treatment) may also be present and should be specified at the time of diagnosis. Other causes of psychotic symptoms that should be excluded are dementia with Lewy bodies (DLB), delirium, schizophrenia, schizoaffective disorder, delusional disorder, and mood disorder with psychotic features. Visual hallucinations tend to be more common but are often minor and less disruptive than delusions. ${ }^{7,14}$ Both hallucinations and psychosis have been reported to persist throughout the course of $\mathrm{PD},{ }^{15,16}$ These psychotic symptoms have been associated with increased caregiver burden, nursing home placement, and risk of death. ${ }^{17-19}$

Despite the high prevalence of hallucinations and delusions in PD, few randomized controlled trials (RCTs) have been published. Previous studies have typically been case studies, case series, retrospective and prospective observational studies, and open-label studies. The limitations inherent with such data create clinical uncertainties.

In 2006, Miyasaki et al ${ }^{20}$ developed and published the American Academy of Neurology (AAN) practice guideline for the management of psychosis in PD in accordance with AAN standards for guideline development. ${ }^{21}$ They concluded that clozapine should be considered for use based on one class I study and one class II study (comparison with quetiapine). ${ }^{22,23}$ Based on a comparative trial of clozapine and quetiapine, ${ }^{23}$ the recommendation was that quetiapine may be considered for use based on a lack of significant difference in effectiveness. Finally, it was recommended to avoid olanzapine because of a lack of response in treating psychotic symptoms and worsening of PD motor symptoms in 2 class II studies. ${ }^{24,25}$

The 2006 guideline included studies published before 2004. Because class I and II evidence was available, weaker, open-labeled studies and the plethora of case reports (class III or IV studies) were not included in the development of the guideline. Based on the guideline, clozapine or quetiapine may be used for hallucinations and psychosis. However, it is not clear which subgroups of patients would benefit from pharmacologic treatment or how long treatment should persist. For example, in Alzheimer's disease, behavioral and psychological symptoms of dementia (BPSD) appear to wax and wane in mild to moderate disease. ${ }^{26,27}$ This allows for discontinuation of treatment or periodic dose reductions to minimize patient exposure to medications. However, in PD, BPSD have been reported to be persistent. ${ }^{15,16}$

The objective of this article was to review data that have appeared in the literature since publication of the AAN guideline regarding the management of hallucinations and psychosis in PD.

\section{PATIENTS AND METHODS}

The AAN guideline is based on studies published before 2004. Therefore, to review the subsequently published literature, a search of the PubMed, CINAHL, and PsychInfo databases was conducted for articles published between January 2004 and June 2010. The search was limited to English language and human studies. The following search terms were used: psychosis, ballucinosis, ballucination, delusion, Parkinson, atypical antipsychotic, neuroleptic, aripiprazole, clozapine, olanzaprine, quetiapine, risperidone, and ziprasidone. All study designs were included except case reports, case series, and studies with $<20$ participants. References from published articles also were searched. Both authors reviewed the identified articles for inclusion in the review. Where disagreement about inclusion occurred, both authors met to review the criteria and resolve the difference of opinion. All published outcomes were included in the analysis of data.

The most commonly used scale in the reviewed studies was the Brief Psychiatric Rating Scale (BPRS). ${ }^{28}$ Other scales included the Baylor Hallucination Questionnaire (BPDHQ; not validated), the Clinical Global Impression of Improvement (CGI) or Severity of Ill- 
ness (CGI-SI) ${ }^{29}$ the Hoehn and Yahr (H\&Y), ${ }^{30}$ the Mini-Mental State Examination (MMSE), ${ }^{31}$ the Neuropsychiatry Inventory (NPI-Total [sum of all scores] and NPI-2 subscale [sum of hallucinations and delusions item scores]), 32 Parkinson's Psychosis Rating Scale (PPRS), ${ }^{33}$ the Positive and Negative Symptoms Scale (PANSS), ${ }^{34}$ and the UPDRS (total, motor, and ADL).$^{35}$ All of these scales except the CGI assess the severity and frequency of psychotic symptoms. Although all are frequently used in PD psychosis research, only the PPRS is validated in a PD population. The PPRS, BPDHQ, and CGI require application by specially trained clinicians; no standardized cutoffs exist for these scales as they do for the MMSE and other scales.

Scores for the scales used in these studies were as follows: BPDHQ (each item rated 0-4; higher scores indicate worse symptoms); BPRS (range, 0-108 if using $0-6$ scale or 18-126 if using 1-7 scale; each of 18 items rated from not present to extremely severe); CGI (range, $0-7 ; 0=$ not assessed, $4=$ no change, $7=$ very much worsened); CGI-SI (range, $0-7 ; 0=$ not assessed, $1=$ normal, 7 = extremely ill); H\&Y (range, 1-5; lower scores indicate higher functioning); Index of ADL ( 6 domains of functioning; higher scores indicate worse function [secondary outcome]); MMSE (range, $0-30 ;<10=$ severe, $10-20=$ moderate, $20-26$ = mild, $>26$ = normal; higher scores indicate higher function); NPI-Total total sum of scores (range, $0-120$; subscales for frequency [4-point scale; $4=$ very frequent] and severity [3-point scale; $3=$ severe]); NPI-2 ( $\geq 1$ on hallucination or delusion subscales considered clinically important [secondary outcome]); PANSS (range, 16-112; $58=$ mildly ill, $75=$ moderately ill, $95=$ markedly ill, $116=$ severely ill; each item rated $1-7$, with 1 being absence of symptoms and 7 being most severe symptom); PPRS (range, 6-24); UPDRS-Total (range, 0-108; each item rated from normal [0] to severe [4]; decreases in score indicate improvement); UPDRS-ADL subscale ( 13 items rated on a scale of $0-4$, with 0 representing normal or best status); and UPDRS-Motor subscale (18 items; lower scores indicate better motor function).

\section{RESULTS}

Thirteen studies were included in the review: 3 studies of clozapine, ${ }^{36-38} 7$ studies of quetiapine, ${ }^{39-45} 2$ headto-head trials comparing quetiapine and clozapine, ${ }^{46,47}$ and 1 noncomparative trial of clozapine or quetiapine interventions. ${ }^{48}$ Baseline demographic characteristics of the patients in these studies are presented in Table I.
Most of the studies included participants with a mean age in the early to mid $70 \mathrm{~s}$ and a mean duration of $\mathrm{PD}$ typically $>10$ years. Studies varied in the reporting of PD function based on the UPDRS-Total score and the $\mathrm{H} \& \mathrm{Y}$ score. The mean levodopa doses ranged from 300 to $788 \mathrm{mg} / \mathrm{d}$; most doses were between 600 and $788 \mathrm{mg} / \mathrm{d}$. Only one study ${ }^{40}$ reported low doses (median, $300-400 \mathrm{mg} / \mathrm{d}$ ). Three studies ${ }^{37,41,45}$ did not report mean levodopa doses. The duration of therapy in the studies of PD psychosis was typically $\sim 3$ months but ranged from 2.5 to 60 months. Studies were conducted with clozapine and/or quetiapine; no studies of aripiprazole, olanzapine, risperidone, or ziprasidone met the inclusion criteria. Based on the reported UPDRS-Total, H\&Y, and UPDRS-Motor scores, high daily levodopa doses, and the duration of disease, study patients were typically classified as having moderate to advanced PD. However, definitions of psychosis varied among studies, even after publication of the 2007 Ravina criteria. ${ }^{14}$

The study designs and outcomes of the identified trials are presented in Tables II to V. Most of the studies used the change in BPRS-Total score from baseline to end point as the primary outcome measure of psychotic symptoms and the UPDRS-Motor score to determine the influence of treatment on motor symptoms and tolerability. The mean BPRS scores at baseline ranged from 11 to 40.5 ; higher scores indicated more severe symptoms. Six studies ${ }^{36-39,43,47}$ did not report baseline BPRS scores. One study ${ }^{47}$ reported the following baseline NPI scores: hallucination frequency = clozapine 3.0 , quetiapine 3.1 ; hallucination severity $=$ clozapine 1.3 , quetiapine 1.4 ; delusions/frequency = clozapine 3.0 , quetiapine 1.5 ; and delusions/severity = clozapine 2.0, quetiapine 1.5 (all, $P=\mathrm{NS}$ ). One study ${ }^{36}$ reported a baseline PANSS score of 15.3 in the placebo group and 17.8 in the clozapine group ( $P$ value not reported). Thus, 4 studies $^{37-39,43}$ did not present information regarding baseline frequency or severity of psychotic symptoms. Other outcome measures included the BPDHQ, CGI, nursing home placement, and death.

Adverse effects were rare in these studies. However, interpretation of the safety data was limited by the small sample sizes, which might have decreased the power to detect rare but serious adverse effects. In addition, adverse effects were poorly described among the identified studies. Six of the 13 studies reported actual numbers of patients experiencing worsening of motor symptoms. ${ }^{36,38-41,46}$ Among these studies, $11.8 \%$ $(28 / 238)$ of the patients were reported to experience worsening of motor symptoms; of the 28 patients, 3 
Eng, Marty L. and Welty, Timothy E. (1999) Management of Hallucinations and Psychosis in Parkinson's Disease.

Am J Geriat Pharm. 8(4), 316-330. PMID: 20869621. Publisher's official version: <http://dx.doi.org/10.1016/j.amjopharm.2010.08.004> . Open Access version: http://kuscholarworks.ku.edu/dspace/.

\begin{tabular}{l|l}
\hline The American Journal of Geriatric Pharmacotherapy & M.L. Eng and T.E. Welty
\end{tabular}

Table I. Baseline demographic characteristics of the study populations. ${ }^{36-48}$

\begin{tabular}{|c|c|c|c|c|c|c|}
\hline Study & Mean Age, Years & UPDRS-Total & $H \& Y$ & UPDRS-Motor & $\begin{array}{c}\text { Levodopa } \\
\text { Dosage, } \mathrm{mg} / \mathrm{d}\end{array}$ & $\begin{array}{l}\text { PD Duration, } \\
\text { Years }\end{array}$ \\
\hline \multicolumn{7}{|c|}{ Clozapine Studies } \\
\hline $\begin{array}{l}\text { Pollak et al, } \\
2004^{36}\end{array}$ & $\begin{array}{c}\text { Clozapine, 71.2; } \\
\text { placebo, } 72.8\end{array}$ & $\begin{array}{c}\text { Clozapine, 52.6; } \\
\text { placebo, } 52.7\end{array}$ & $\begin{array}{c}\text { Clozapine, } 3.3 ; \\
\text { placebo, } 3.1\end{array}$ & $\begin{array}{c}\text { Clozapine, 31.5; } \\
\text { placebo, } 31.4\end{array}$ & $\begin{array}{c}\text { Clozapine, 788; } \\
\text { placebo, } 733\end{array}$ & $\begin{array}{c}\text { Clozapine, 12.1; } \\
\text { placebo, } 11.3\end{array}$ \\
\hline $\begin{array}{l}\text { Fernandez et al, } \\
2004^{37}\end{array}$ & 76 & NA & 3.5 & 39.4 & NA & 14.2 \\
\hline $\begin{array}{l}\text { Gomide et al, } \\
2008^{38}\end{array}$ & 64 & 55 & 3 & NA & 762.5 & 13.8 \\
\hline \multicolumn{7}{|c|}{ Quetiapine Studies } \\
\hline $\begin{array}{l}\text { Mancini et al, } \\
2004^{39}\end{array}$ & 69.4 & NA & $\begin{array}{l}2.9 \text { (on), } \\
3.6 \text { (off) }\end{array}$ & $\begin{array}{l}35.2 \text { (on), } \\
50.8 \text { (off) }\end{array}$ & 714.7 & 11.7 \\
\hline $\begin{array}{l}\text { Juncos et al, } \\
2004^{40}\end{array}$ & 73 & 55.8 & NA & 27.8 & Median, $300-400$ & NA \\
\hline $\begin{array}{l}\text { Ondo et al, } \\
2005^{41}\end{array}$ & $\begin{array}{l}\text { Quetiapine, 74; } \\
\text { placebo, } 71\end{array}$ & NA & NA & $\begin{array}{l}\text { Quetiapine, 34; } \\
\text { placebo, } 31\end{array}$ & NA & $\begin{array}{l}\text { Quetiapine, 12; } \\
\text { placebo, } 9\end{array}$ \\
\hline $\begin{array}{l}\text { Prohorov et al, } \\
2006^{42}\end{array}$ & 75.5 & NA & NA & $\begin{array}{l}\text { Dementia, 40.9; } \\
\text { no dementia, }\end{array}$ & 685.3 & 10.3 \\
\hline $\begin{array}{l}\text { Klein et al, } \\
2006^{43}\end{array}$ & 76.1 & NA & NA & 38.5 & 685.3 & 10.3 \\
\hline $\begin{array}{l}\text { Rabey et al, } \\
2007^{44}\end{array}$ & $\begin{array}{c}\text { Quetiapine, 75.5; } \\
\text { placebo, } 74.5\end{array}$ & $\begin{array}{c}\text { Quetiapine, 64.9; } \\
\text { placebo, 69.2 }\end{array}$ & $\begin{array}{c}\text { Quetiapine, 3.2; } \\
\text { placebo, 3.2 }\end{array}$ & $\begin{array}{l}\text { Quetiapine, 37; } \\
\text { placebo, } 39.5\end{array}$ & $\begin{array}{c}\text { Quetiapine, 594.6; } \\
\text { placebo, } 766.1\end{array}$ & $\begin{array}{c}\text { Quetiapine, 10.5; } \\
\text { placebo, } 10.6\end{array}$ \\
\hline $\begin{array}{l}\text { Kurlan et al, } \\
2007^{45}\end{array}$ & $\begin{array}{c}\text { Quetiapine, 73.5; } \\
\text { placebo, 74.1 }\end{array}$ & & NA & $\begin{array}{c}\text { Quetiapine, 17.2; } \\
\text { placebo, 17.5 }\end{array}$ & NA & NA \\
\hline \multicolumn{7}{|c|}{ Comparison Studies } \\
\hline $\begin{array}{l}\text { Morgante et al, } \\
2004^{46}\end{array}$ & $\begin{array}{c}\text { Quetiapine, 70; } \\
\text { clozapine, } 69\end{array}$ & & NA & $\begin{array}{l}\text { Quetiapine, 53; } \\
\text { clozapine, } 58\end{array}$ & $\begin{array}{c}\text { Quetiapine, 710; } \\
\text { clozapine, } 687\end{array}$ & $\begin{array}{c}\text { Quetiapine, 8.3; } \\
\text { clozapine, } 9.6\end{array}$ \\
\hline $\begin{array}{l}\text { Merims et al, } \\
2006^{47}\end{array}$ & 71.8 & $\begin{array}{l}\text { Clozapine, 78.4; } \\
\text { quetiapine, } 75.3\end{array}$ & 2.9 & NA & $\begin{array}{l}\text { Clozapine, } 691 ; \\
\text { quetiapine, } 778\end{array}$ & 10.3 \\
\hline \multicolumn{7}{|c|}{ Noncomparative Trial of Clozapine or Quetiapine Interventions } \\
\hline $\begin{array}{l}\text { Goetz et al, } \\
2008^{48}\end{array}$ & 72 & NA & NA & 40 & 802 & 12 \\
\hline
\end{tabular}

UPDRS-Total = Unified Parkinson's Disease Rating Scale-Total (range, 0-108; each item rated from normal [0] to severe [4]; decreases in score indicate improvement); $\mathrm{H} \& Y=$ Hoehn and Yahr (range, 1-5; lower scores indicate higher functioning); UPDRS-Motor subscale (18-items; lower scores indicate better motor function); $\mathrm{PD}=$ Parkinson's disease; $\mathrm{NA}=$ not assessed.

received placebo and 25 received an atypical antipsychotic medication. However, all of these worsenings were described by the study investigators as not sufficient to alter or discontinue treatment. The remaining 7 studies, which did not report actual numbers, made statements such as "no significant difference in UPDRS (motor)" scores. ${ }^{37,42-45,47,48}$

\section{Clozapine Studies}

Three studies examined clozapine in the treatment of psychosis in patients with PD. ${ }^{36-38}$ In 2004, Pollak et $\mathrm{al}^{36}$ conducted a multiphase RCT in 60 patients with PD to determine the effectiveness and tolerability of clozapine in drug-induced psychosis. At baseline, the mean age of study participants was $\sim 7$ years, the dura- 
tion of $\mathrm{PD}$ was $\sim 11$ to 12 years, $\mathrm{H} \& \mathrm{Y}$ stages were 3.1 to 3.3 , and the UPDRS-Total score was 52 points. The mean baseline PANSS score was 17.8 for the clozapine group and $\mathbf{1 5 . 3}$ for the placebo group. Treatment occurred in 4 phases. Phase 1 was a screening period, during which patients were started on a low dose of clozapine ( $6.25 \mathrm{mg}$ once daily) or placebo at bedtime. Phase 2 was a dose-titration period. Doses were increased at a rate of $12.5 \mathrm{mg} / \mathrm{d}$ to a maximum of 50 $\mathrm{mg} / \mathrm{d}$. The mean dose at the end of phase 2 was 35.8 $\mathrm{mg} / \mathrm{d}$ (range, $12.5-50 \mathrm{mg} / \mathrm{d}$ ). The dose of clozapine could be reduced during phase 2 if the patient experienced adverse effects. If no improvement was experienced after 2 weeks, patients entered phase 3 , which was open labeled. Patients in the clozapine group continued with dose titration up to a maximum of 100 $\mathrm{mg} / \mathrm{d}$, and those in the placebo group were started on clozapine. The mean dose during phase 3 in those who previously received clozapine was $40 \mathrm{mg} / \mathrm{d}$ (range, $12.5-100 \mathrm{mg} / \mathrm{d}$ ); the mean dose in those who previously received placebo was $42.5 \mathrm{mg} / \mathrm{d}$ (range, 6.25 $100 \mathrm{mg} / \mathrm{d}$ ). Finally, if patients exhibited "mental normalization," as evidenced by a score of $<3$ on PANSS items P1 and P3 (which correspond to hallucinations and delusions), clozapine was discontinued over a week and the patients were followed for 3 weeks. The completion rate was poor $(76.7 \% ; 46 / 60)$. Results of the study are summarized in Table II. At the end of phase 2 , patients who received clozapine had a -1.8 -point improvement in CGI score over baseline $(P<0.001)$ and patients who received placebo had a 0.6 -point improvement $(P=0.011)$. The change in PANSS score from baseline to the end of phase 2 decreased by 5.6 points $(P<0.001)$ in the clozapine group and by -0.8 points $(P=\mathrm{NS})$ in the placebo group. Statistically significant differences were also found between the groups in the changes in the CGI (1.8-point improvement for clozapine vs 0.6 -point improvement for placebo; $P<$ 0.001 ) and the PANSS ( 5.6 for clozapine vs 0.8 for placebo; $P<0.001$ ). At the end of phase 3 , the CGI and PANSS scores continued to improve in patients in the clozapine titration group, by -2.5 points $(P<$ $0.001)$ and -7.7 points $(P<0.001)$, respectively. At the end of phase 3 , the group that switched from placebo to clozapine had a -1.8-point improvement in CGI score $(P<0.001)$ and a -4.8 -point improvement in PANSS score $(P<0.001)$. Twenty-five patients entered phase 4 for withdrawal of therapy. Relapse was observed within 3 months in $76.0 \%(19 / 25)$ of patients. Overall, adverse effects and serious adverse effects occurred more frequently in the clozapine group than in the placebo group. Somnolence at the end of phase 2 occurred more frequently in clozapine users $(53.1 \%$; $17 / 32)$ than in placebo users $(17.9 \% ; 5 / 28)$. Somnolence in phase 3 occurred more frequently in patients who switched from placebo to clozapine $(44.0 \%$; $11 / 25)$ than in those who continued clozapine titration $(10.0 \% ; 3 / 30)(P$ value not reported). Worsening of PD symptoms at the end of phase 2 was reported in $21.9 \%(7 / 32)$ of clozapine users and $3.6 \%(1 / 28 ; P=$ NS) of placebo users. At the end of phase 3, worsening of PD was not substantially different between patients in the clozapine-titration group $(13.3 \% ; 4 / 30)$ and those switching from placebo to clozapine $(12.0 \%$ [3/25]; $P$ value not reported). Sialorrhea also occurred more frequently in the clozapine group $(9.4 \% ; 3 / 32)$ than in the placebo group $(0 \% ; 0 / 28)$ at the end of phase 2 and occurred in $20.0 \%(5 / 25)$ of those who switched from placebo to clozapine versus none of those continuing clozapine titration $(0 \% ; 0 / 30)$ at the end of phase 3 . Serious adverse effects occurred in 4 patients (sudden death, death from pneumonia, aggression with delusions, and confusion with delusions; 1 patient each). These events led to discontinuation of treatment in phase 3 , but the investigators did not specify whether they were deemed to be treatment related.

Fernandez et $\mathrm{al}^{37}$ also reported on clozapine use in patients with PD and psychosis. This descriptive retrospective chart review included 39 patients with PD and psychosis; $79.5 \%(31 / 39)$ of the patients had probable PD, $12.8 \%(5 / 39)$ had DLB, and 7.7\% (3/39) had other parkinsonian features. More than half of the cohort $(56.4 \% ; 22 / 39)$ also had dementia. Outcomes were nursing home placement and mortality after 5 years. The mean age of the cohort was 76 years, and the mean duration of PD was 14.2 years. The mean dose of clozapine was $47 \mathrm{mg} / \mathrm{d}$, with a mean treatment duration of 5 years. The investigators reported nursing home placement for $33.3 \%(13 / 39)$ of patients and a mortality rate of $43.6 \%(17 / 39)$ at 5 years. Partial/ good response was reported for $84.6 \%(33 / 39)$ of the patients, and $12.8 \%(5 / 39)$ had complete resolution of psychosis with clozapine treatment $(P$ value not reported). The measurements of response were not described in the publication. Significant worsening of motor symptoms over baseline based on UPDRS-Motor scores ( 39.5 vs $45.7 ; P<0.001)$ was reported at the end of the study. This was also true for H\&Y scores ( 3.4 vs $3.9 ; P=0.006)$. However, it was also noted that none of the patients discontinued clozapine treatment because of worsening motor function. The most com- 
Eng, Marty L. and Welty, Timothy E. (1999) Management of Hallucinations and Psychosis in Parkinson's Disease.

Am J Geriat Pharm. 8(4), 316-330. PMID: 20869621. Publisher's official version: <http://dx.doi.org/10.1016/j.amjopharm.2010.08.004> . Open Access version: http://kuscholarworks.ku.edu/dspace/.

\begin{tabular}{l|l}
\hline The American Journal of Geriatric Pharmacotherapy & M.L. Eng and T.E. Welty
\end{tabular}

mon adverse effects were sedation and sialorrhea $(30 \%$ and $10 \%$, respectively).

Gomide et $\mathrm{al}^{38}$ retrospectively reviewed the charts of 43 patients with PD who used clozapine: 17 with dyskinesia, 15 with psychosis, and 11 with both diagnoses. The purpose of this study was to describe the characteristics of clozapine users in a Brazilian cohort. Although "improvement" was reported, it is not clear what measures were used to determine improvement. Of the patients with psychosis, $73.3 \%(11 / 15)$ had at least partial improvement and $13.3 \%(2 / 15)$ experienced no change. (Two patients were unaccounted for in the original article.) This appeared to be a global impression among clinicians. However, the text was ambigu-

Table II. Clozapine studies. ${ }^{36-38}$

\begin{tabular}{|c|c|c|c|c|c|c|c|c|}
\hline \multirow[b]{2}{*}{ Study } & \multirow[b]{2}{*}{ Blind } & \multirow{2}{*}{$\begin{array}{l}\text { Cohort } \\
\text { Size }\end{array}$} & \multirow{2}{*}{$\begin{array}{c}\text { Completion } \\
\text { Rate, } \%\end{array}$} & \multirow{2}{*}{$\begin{array}{c}\text { Mean Dose } \\
\text { (Range), } \\
\text { mg/d }\end{array}$} & \multirow{2}{*}{$\begin{array}{c}\text { Duration, } \\
\text { Months }\end{array}$} & \multirow{2}{*}{$\begin{array}{l}\text { Primary } \\
\text { Outcome } \\
\text { Measures }\end{array}$} & \multicolumn{2}{|l|}{ Outcomes } \\
\hline & & & & & & & Primary & Secondary \\
\hline $\begin{array}{l}\text { Pollak et al, } \\
2004^{36}\end{array}$ & $\begin{array}{l}\text { For } \\
\text { phase } 2 \\
\text { only }\end{array}$ & 60 & 76.7 & $\begin{array}{c}\text { Phase 2: } \\
\text { clozapine, } \\
35.8 \\
(12.5-50) ; \\
\text { placebo, } \\
41.7(6-50) ; \\
\text { phase } 3: \\
\text { clozapine, } \\
40 \\
(12.5-100) ; \\
\text { placebo, } \\
425\end{array}$ & $\begin{array}{c}\text { Phase 2, 1; } \\
\text { phase 3, 3; } \\
\text { phase 4, } \\
0.25\end{array}$ & $\begin{array}{l}\text { CGI, } \\
\text { PANSS }\end{array}$ & $\begin{array}{l}\text { Phase } 2 \text { change in CGI } \\
\text { from baseline: clozapine, } \\
P<0.001 \text {; placebo, } \\
P<0.01 \text {; phase } 2 \text { change } \\
\text { in PANSS from baseline: } \\
\text { clozapine, } P<0.001 \text {; } \\
\text { placebo, } P<0.127 \\
\text { between treatment } \\
\text { groups; differences from } \\
\text { baseline on both CGl } \\
\text { and PANSS, } P<0.001 \text {; } \\
\text { phase } 3 \text { change in CGI } \\
\text { from baseline: clozapine } \\
\text { to clozapine, } P<0.001 \text {; } \\
\text { placebo to clozapine, } \\
P<0.001 \text {; phase } 3 \text { change } \\
\text { in PANSS from baseline: } \\
\text { clozapine to clozapine, } \\
P<0.001 \text {; placebo to } \\
\text { clozapine, } P<0.001\end{array}$ & $\begin{array}{l}76 \%(19 / 25) \\
\text { Relapsed in } \\
\text { phase } 4\end{array}$ \\
\hline $\begin{array}{l}\text { Fernandez } \\
\text { et al, } 2004^{37}\end{array}$ & No & 39 & - & 47 & 60 & $\begin{array}{l}\mathrm{NH} \text { admit } \\
5 \text {-year } \\
\text { mortality }\end{array}$ & $\begin{array}{l}33 \% \text { Admit to } \mathrm{NH} \\
44 \% \text { mor tality over } \\
5 \text { years }\end{array}$ & - \\
\hline $\begin{array}{l}\text { Gomide } \\
\text { et al, } 2008^{38}\end{array}$ & No & 43 & - & $\begin{array}{c}69.6 \\
(12.5-225)\end{array}$ & - & - & $\begin{array}{l}26 \% \text { Remained on } \\
\text { clozapine } \times 3.5 \text { years } \\
\text { and } 40 \%<1 \text { year }\end{array}$ & $\begin{array}{c}67.5 \% \\
\text { Improved } \\
\text { psychosis; } \\
60.5 \% \text { noticed } \\
\text { adverse effects; } \\
7 \text { stopped } \\
\text { treatment due } \\
\text { to adverse } \\
\text { effects }\end{array}$ \\
\hline
\end{tabular}

$\mathrm{CGI}=$ Clinical Global Impression of Improvement (range, 0-7; $0=$ not assessed, $4=$ no change, $7=$ very much worsened); PANSS = Positive and Negative Syndrome Scale (range, 16-112; 58 = mildly ill, 75 = moderately ill, 95 = markedly ill, 116 = severely ill; each item rated 1-7, with 1 being absence of symptoms and 7 being most severe symptom); $\mathrm{NH}=$ nursing home. 
Eng, Marty L. and Welty, Timothy E. (1999) Management of Hallucinations and Psychosis in Parkinson's Disease.

Am J Geriat Pharm. 8(4), 316-330. PMID: 20869621. Publisher's official version: <http://dx.doi.org/10.1016/j.amjopharm.2010.08.004> . Open Access version: http://kuscholarworks.ku.edu/dspace/.

M.L. Eng and T.E. Welty $\quad$ The American Journal of Geriatric Pharmacotherapy

ous in describing the assessment of effectiveness; no scales were used to assess psychotic symptoms. The external validity of the study results was limited because data regarding baseline severity of psychotic symptoms was not presented. It was also not clear what differences in care might have occurred within the Brazilian health care system that could introduce potential biases in the results. In terms of tolerability, clozapine treatment was stopped in 20 patients ( 5 due to death, 7 due to adverse effects of clozapine, 2 due to worsening of motor function, and 6 for reasons not described). Adverse effects leading to discontinuation of treatment

Table III. Quetiapine studies. ${ }^{39-45}$

\begin{tabular}{|c|c|c|c|c|c|c|c|c|}
\hline Study & Blind & $\begin{array}{l}\text { Cohort } \\
\text { Size }\end{array}$ & $\begin{array}{l}\text { BPRS- } \\
\text { Total }\end{array}$ & $\begin{array}{l}\text { Completion } \\
\text { Rate, } \%\end{array}$ & $\begin{array}{l}\text { Mean Dose } \\
\text { (Range), mg/d }\end{array}$ & $\begin{array}{l}\text { Duration } \\
\text { (Range), } \\
\text { Months }\end{array}$ & $\begin{array}{l}\text { Primary } \\
\text { Outcome } \\
\text { Measures }\end{array}$ & Results \\
\hline $\begin{array}{l}\text { Mancini et al, } \\
2004^{39}\end{array}$ & No & 35 & NA & 91.4 & 185 & 12 & $\begin{array}{l}\text { UPDRS-III } \\
\text { (motor), } \\
\text { PPRS, } \\
\text { MMSE }\end{array}$ & $\begin{array}{l}\text { UPDRS, } P=N S ; P P R S, \\
P<0.001 ; M M S E, P=N S\end{array}$ \\
\hline $\begin{array}{l}\text { Juncos et al, } \\
2004^{40}\end{array}$ & No & 29 & 17.8 & 86.2 & $\begin{array}{c}62.5 \\
(12.5-400)\end{array}$ & $\begin{array}{c}5.6 \\
(0.4-7.7)\end{array}$ & $\begin{array}{l}\text { BPRS, } \\
\text { NPI-Total, } \\
\text { NPI-2, } \\
\text { CGI-SI }\end{array}$ & $\begin{array}{l}\text { Mean change: BPRS, }-6 \\
(P=0.003) ; \mathrm{NPI}-\mathrm{Total},-7 \\
(P=\mathrm{NS}) ; \mathrm{NPI}-2,-3.9 \\
(P=0.027) ; \mathrm{CGI}-\mathrm{SI},-0.5 \\
(P=0.039)\end{array}$ \\
\hline $\begin{array}{l}\text { Ondo et al, } \\
2005^{41}\end{array}$ & Yes & 31 & 11 & 83.8 & Up to 200 & 3 & $\begin{array}{l}\text { BPDHQ, } \\
\text { UPDRS }\end{array}$ & $\begin{array}{l}\mathrm{BPDHQ}, P=\mathrm{NS} ; \text { UPDRS, } \\
P=\mathrm{NR}\end{array}$ \\
\hline $\begin{array}{l}\text { Prohorov et al, } \\
2006^{42}\end{array}$ & No & 35 & 35.5 & 69 & $\begin{array}{l}\text { Dementia, 150.9; } \\
\text { oo dementia, } 76.3\end{array}$ & 6 & BPRS, CGI & $\begin{array}{l}\text { BPRS: No dementia, } P=N S \text {; } \\
\text { dementia, no change } \\
\text { reported; CGI: improved; } \\
\text { no dementia, } 25 \%(4 / 16) ; \\
\text { no statistics reported }\end{array}$ \\
\hline $\begin{array}{l}\text { Klein et al, } \\
2006^{43} \\
\text { (extension } \\
\text { of study by } \\
\text { Prohorov } \\
\text { et } \text { al }^{42} \text { ) }\end{array}$ & No & 35 & NA & $N A$ & 93 & 24 & CGI & $\begin{array}{l}\text { Overall, } 42.9 \%(15 / 35) \text { rated } \\
\text { as good or partial response; } \\
\text { dementia, } 46.7 \%(7 / 15) \\
\text { had good response; no } \\
\text { dementia, } 44 \%(4 / 9) \text { had } \\
\text { good or partial response }\end{array}$ \\
\hline $\begin{array}{l}\text { Rabey et al, } \\
2007^{44}\end{array}$ & Yes & 58 & $24-26$ & 55 & 119 & 3 & BPRS, CGI & $\begin{array}{l}\text { BPRS: No change; } 9 / 29 \\
\text { (31\%) improved quetiapine, } \\
13 / 27(48 \%) \text { improved } \\
\text { placebo }\end{array}$ \\
\hline $\begin{array}{l}\text { Kurlan et al, } \\
2007^{46}\end{array}$ & Yes & 40 & 26.5 & 75 & 120 & 2.5 & BPRS & $P=\mathrm{NS}$ \\
\hline
\end{tabular}

BPRS = Brief Psychiatric Rating Scale (range, 0-108 if using 0-6 scale or 18-126 if using 1-7 scale; each of 18 items rated from not present to extremely severe); $\mathrm{NA}=$ not assessed; UPDRS = Unified Parkinson Disease Rating Scale (range, 0-108; each item rated from normal [0] to severe [4]; decreases in score indicate improvement); UPDRS-III (motor) = subsection of UPDRS that assesses motor function ( 14 items using a scale of $0-4$, with 4 being the worst level of functioning); PPRS = Parkinson Psychosis Rating Scale (range, 6-24); MMSE = Mini-Mental State Examination (range, 0-30; $<10=$ severe, 10-20 = moderate, 20-26 $=$ mild, $>26$ = normal; higher scores indicate higher function); NPI-Total = Neuropsychological Inventory total sum of scores (range, $0-120$; subscales for frequency [4-point scale; 4 =very frequent] and severity [3-point scale; $3=$ severe]); $\geq 1$ on hallucination or delusion subscales considered clinically important); $\mathrm{NPI}-2=\mathrm{NPI}$ sum of hallucinations and delusions item scores ( 21 on hallucination or delusion subscales considered clinically important); CGI-SI = Clinical Global Impression-Severity of Illness (range, $0-7 ; 0=$ not assessed, $1=$ normal, $7=$ extremely ill); BPDHQ = Baylor PD Hallucination Questionnaire (each item rated 0-4; higher scores indicate worse symptoms); $N R=$ not reported; $C G I=$ Clinical Global Impression of Improvement (range, $0-7 ; 0=$ not assessed, $4=$ no change, $7=$ very much worsened). 
Eng, Marty L. and Welty, Timothy E. (1999) Management of Hallucinations and Psychosis in Parkinson's Disease. Am J Geriat Pharm. 8(4), 316-330. PMID: 20869621. Publisher's official version: <http://dx.doi.org/10.1016/j.amjopharm.2010.08.004> . Open Access version: http://kuscholarworks.ku.edu/dspace/.

included neutropenia ( 3 patients), thrombocytopenia (1), severe constipation with bowel obstruction (1), hallucination (1), and agitation (1). Thus, adverse effects in this study appeared to limit the effectiveness of clozapine given that $46.5 \%(20 / 43)$ of patients had to stop treatment.

\section{Quetiapine Studies}

Seven quetiapine studies ${ }^{39-45}$ were included in this review (Table III). Mancini et $\mathrm{al}^{39}$ reported on the effects of quetiapine on hallucinations and delusions using the PPRS in an uncontrolled, open-label study. The study included 35 patients with advanced PD and mental disorders, including hallucinations, delusions, confusion, and agitation. (No further breakdown of the demographic characteristics was provided in the article.) The mean age of the study group was 68.4 years, the mean duration of PD was 11.7 years, and the mean quetiapine dose was $185 \mathrm{mg} / \mathrm{d}$ (range, 100-400 $\mathrm{mg} / \mathrm{d}$ ) over 12 months. The mean H\&Y and UPDRSMotor scores during on/off periods (with/without symptoms) were $2.9 / 3.6$ and $35.2 / 50.8$, respectively. Improvements in PPRS scores, hallucinations, and delusions were reported after 12 months (all, $P<0.001$ ); no substantial worsening of UPDRS-Motor scores occurred ( $P$ value not reported).

In a 24-week, single-center, uncontrolled, open-label study, Juncos et $\mathrm{al}^{40}$ examined 29 patients with PD and psychosis (including stable dementia and depression) who did not wish to undergo the extensive laboratory testing and monitoring needed with clozapine or who did not benefit from previous atypical antipsychotic treatment. The reasons for those treatment failures are presented in Table IV. Patients may have had $>1$ reason for treatment failure. The investigators did not describe how many patients may have had multiple failures or why the number of patients with treatment failures was greater than the number of patients they studied; $86.2 \%(25 / 29)$ of the patients completed this 24 -week study. The mean quetiapine dose was 62.5 $\mathrm{mg} / \mathrm{d}$ (range, $12.5-400 \mathrm{mg} / \mathrm{d}$ ). The primary outcome was the change in BPRS score after 24 weeks of treatment. Secondary outcomes included NPI-Total, NPI2 , and CGI. Improvements in the BPRS and CGI scores were significant $(P=0.003$ and $P=0.039$, respectively), but the effects on the NPI-Total score did not reach statistical significance. It is unclear why a significant treatment difference in NPI-Total score was not found. However, the improvement in NPI-2 score was statistically significant $(P=0.027)$. Significant improvement in CGI-SI score was reported in $51.7 \%$ $(15 / 29)$ of patients, no substantial change was noted in $13.8 \%(4 / 29)$, and worsening was noted in $34.5 \%$ $(10 / 29)$. The most common adverse effects reported were dizziness $(13.8 \% ; 4 / 29)$ and postural hypotension $(6.9 \% ; 2 / 29)$. Other adverse effects were characterized as mild to moderate and unrelated to treatment. The mean MMSE score was 21.2; no significant difference in MMSE score was found between the baseline and week- 24 assessments.

In 2005 , Ondo et al ${ }^{41}$ conducted an RCT in 31 patients with $\mathrm{PD}$ and hallucinations ( 21 received quetiapine and 10 received placebo); $83.9 \%(26 / 31)$ of the patients completed the study. Treatment was discontinued for $19.0 \%(4 / 21)$ of patients in the quetiapine group ( 2 for unrelated serious illness and 2 for lack of effect/poor compliance). Treatment was also discontinued for $20.0 \%(2 / 10)$ of patients in the placebo group (for unrelated serious illness). The investigators stated that the dropouts were not included in the statistical analysis. The primary outcomes were the BPDHQ and the UPDRS. The mean quetiapine doses were

Table IV. Previous treatment failures for patients enrolled in the study by Juncos et al $(\mathrm{N}=29) .{ }^{40}$

\begin{tabular}{lcccc}
\hline & & \multicolumn{3}{c}{ Reason for Treatment Failure } \\
\cline { 3 - 5 } Drug & $\begin{array}{c}\text { No. of Patients Who } \\
\text { Experienced Treatment Failure* }\end{array}$ & $\begin{array}{c}\text { Unwilling to Undergo } \\
\text { Testing and Monitoring }\end{array}$ & $\begin{array}{c}\text { Lack of } \\
\text { Effectiveness }\end{array}$ & Intolerance \\
\hline Clozapine & 17 & 2 & 13 & 15 \\
Olanzapine & 14 & NA & 12 & 26 \\
Risperidone & 9 & NA & 3 & 9 \\
\hline
\end{tabular}

$\mathrm{NA}=$ not applicable.

*Patients may have experienced treatment failure for $>1$ reason. 
$\leq 200 \mathrm{mg} / \mathrm{d}$ over 3 months. No significant difference was found between the groups based on the BPDHQ. Lack of change in the BPRS score (the secondary outcome) affirmed the lack of treatment difference in this study. The lack of treatment response could be explained by the inclusion of patients with relatively mild symptoms at baseline (BPRS score was 11 compared with $>20$ in other studies). ${ }^{42,44-47}$ Furthermore, the investigators reported a post hoc analysis of power at 0.22 and effect size of 0.35 , which indicates that the study might have been underpowered. No substantial differences in the changes in the UPDRS-ADL or UPDRS-Motor scores were found between the groups ( $P$ values not reported). This suggested that PD features did not worsen with treatment.

In 2006, Prohorov et $\mathrm{al}^{42}$ investigated in an openlabel study whether dementia would affect the response to quetiapine in patients with drug-induced psychosis over 6 months. Thirty-five patients with PD and psychosis were included (19 with and 16 without dementia). The mean MMSE score was 16.3 in the group with dementia and 26.1 in the group without dementia. The mean patient age was 75.5 years, and the mean duration of PD was 10.3 years. Mixed hallucinations and delusions were present in $65.7 \%(23 / 35)$ of the patients. Most $(68.6 \% ; 24 / 35)$ of the patients completed the study; $26.3 \%(5 / 19)$ of the patients with dementia and $37.5 \%(6 / 16)$ of the patients without dementia dropped out of the study $(P=\mathrm{NS})$. Reasons for dropping out included lack of response in $22.9 \%$ $(8 / 35)$ of patients and adverse effects (somnolence or orthostatic hypotension) in $8.6 \%(3 / 35)$ of patients. Effectiveness results based on BPRS scores (the primary outcome) and CGI scores were conflicting. Among the patients who completed the study, there was no significant difference in BPRS scores between the groups (no statistics were reported). However, results based on the CGI suggested that PD patients with dementia were more likely than those without dementia to benefit from quetiapine therapy for drug-induced psychosis (50\% vs $40 \%$, respectively; $P$ value not reported). Quetiapine doses ranged from 76 to $150 \mathrm{mg} / \mathrm{d}$ over 24 weeks. Doses tended to be higher in the group with dementia $(150.9 \mathrm{mg} / \mathrm{d})$ than in the group without dementia $(76.3 \mathrm{mg} / \mathrm{d} ; P<0.03)$. Titration in the dementia group took $\sim 2$ weeks longer than in the group without dementia ( 5.5 vs 2.3 weeks, respectively), but treatment duration was the same ( 24 weeks) for both groups. Final mean doses were $205 \mathrm{mg} / \mathrm{d}$ in the dementia group and $258.3 \mathrm{mg} / \mathrm{d}$ in the group without dementia. Patients with dementia experienced a slight worsening of symptoms based on the UPDRS-Motor scores (from 40.4 to $45.7 ; P=\mathrm{NS}$ ), whereas those without dementia did not experience any worsening of motor function (from 35.7 to $35.0 ; P$ value not reported).

Klein et $\mathrm{al}^{43}$ reported on the response to treatment with open-labeled quetiapine over 24 months to evaluate the long-term effects on drug-induced psychosis. This appeared to be a continuation of the Prohorov study. ${ }^{42}$ Thirty-five patients (19 with dementia, 16 without) were recruited. The mean age was 76.1 years, and the mean duration of PD was 10.3 years. Of the 35 patients, $11(31.4 \%)$ completed the 2-year study, 7 of whom had dementia. Based on CGI scores (the primary outcome measure), $25.7 \%(9 / 35)$ of the patients reported good response to quetiapine, $5.7 \%(2 / 35)$ reported partial response, and $8.6 \%(3 / 35)$ stopped taking quetiapine because of improvement (medication no longer required). The mean dose of quetiapine was $93 \mathrm{mg} / \mathrm{d}$. Caregivers served as the primary source of global impression. No psychometric testing was reported to support the changes in global impression. Twelve patients (34.3\%) did not respond to quetiapine therapy and were switched to clozapine therapy; all 12 responded to the switch (no statistics were reported). Three other patients $(8.6 \%)$ had clozapine added to their quetiapine therapy, but none of those patients responded. Characteristics of these 3 patients were not included in the published article.

Rabey et $\mathrm{al}^{44}$ conducted an RCT in 58 patients with PD and psychosis, $79.3 \%$ (46/58) of whom were characterized as having severe psychotic symptoms that significantly affected their quality of life. Patients were further subdivided into groups with and without dementia (29 in each group). This study lasted 3 months. The primary outcome was the change in BPRS and CGI scores from baseline. The mean dose of quetiapine was $119 \mathrm{mg} / \mathrm{d}$. After 3 months of treatment, no substantial difference was found in BPRS scores between the quetiapine and placebo groups or between the groups with and without dementia (no statistics were reported). Improvement was seen in $30.0 \%(9 / 30)$ of the patients who received quetiapine and $46.4 \%(13 / 28)$ of those who received placebo. Although numerically this appears to favor placebo, no statistical analysis was reported to assess significance. No treatment difference was found based on the BPRS subitems of hallucinations and delusions or the UPDRS-Motor scores. Somnolence was reported in $23.3 \%(7 / 30)$ of patients in the quetiapine group and $7.1 \%(2 / 28)$ of patients in the placebo group; $6.7 \%(2 / 30)$ of patients in the que- 
Eng, Marty L. and Welty, Timothy E. (1999) Management of Hallucinations and Psychosis in Parkinson's Disease.

Am J Geriat Pharm. 8(4), 316-330. PMID: 20869621. Publisher's official version: <http://dx.doi.org/10.1016/j.amjopharm.2010.08.004> .

Open Access version: http://kuscholarworks.ku.edu/dspace/.

tiapine group stopped treatment because of somnolence. Orthostatic hypotension was reported in $3.3 \%$ $(1 / 30)$ of patients taking quetiapine and none $(0 \%$; $0 / 28$ ) of those taking placebo. Eleven patients were hospitalized during this study because of urinary-tract infections (4 patients), syncope (2), acute psychosis (2), hip fracture (2), or chest pain (1). Only urinary-tract infections and chest pain occurred more frequently in the quetiapine group than the placebo group. Statistical significance was not reported, and the investigators did not indicate whether these hospitalizations were considered to be treatment related. This study had a poor completion rate (55\%).

Kurlan et $\mathrm{al}^{45}$ conducted a multicenter RCT in 40 patients with PD ( 9 with dementia, 8 with Alzheimer's disease, and 23 with DLB). The investigators sought to determine the effectiveness of quetiapine in the treatment of psychosis or agitation as measured by the change in BPRS score after 10 weeks of treatment. The mean dose was $120 \mathrm{mg} / \mathrm{d}$ (dose range not reported). The investigators were allowed to use up to $150 \mathrm{mg}$ BID and were encouraged to titrate in increments of $25 \mathrm{mg} / \mathrm{d}$ every 2 days to at least $100 \mathrm{mg} / \mathrm{d}$. The study duration was 2.5 months, and the completion rate was $75 \%$ ( $85 \%$ in the quetiapine group, $65 \%$ in the placebo group). After 10 weeks of therapy, no significant difference in BPRS scores was found between the 2 groups. An 8.2-point improvement was reported for the quetiapine group, which is consistent with the magnitude of effect seen in clozapine arms of other trials. ${ }^{22}$ A large treatment effect (6.1 points) was seen in the placebo group, which might account for the lack of statistical difference between the 2 groups. In addition, the investigators reported a lack of statistical difference in global ratings of change, which also supports a lack of treatment difference between placebo and quetiapine. No significant differences were found between the subgroups of patients with dementia, Alzheimer's disease, or DLB. The study sample size was small. Some patients without PD were included in the study, and data were not available to adjust the analysis to exclude these individuals.

\section{Comparison Studies}

Two clinical trials ${ }^{46,47}$ were head-to-head comparisons of clozapine and quetiapine (Table V). In 2004,

Table V. Head-to-head studies of quetiapine versus clozapine. 46,47

\begin{tabular}{|c|c|c|c|c|c|c|c|c|}
\hline Study & Blind & $\begin{array}{l}\text { Cohort } \\
\text { Size }\end{array}$ & BPRS-Total & $\begin{array}{l}\text { mpletion } \\
\text { Rate, \% }\end{array}$ & $\begin{array}{c}\text { Mean Dose } \\
\text { (Range), mg/d }\end{array}$ & $\begin{array}{c}\text { Duration, } \\
\text { Months }\end{array}$ & $\begin{array}{c}\text { Primary } \\
\text { Outcome } \\
\text { Measures }\end{array}$ & Results \\
\hline $\begin{array}{l}\text { Morgante } \\
\text { et al, } \\
2004^{46}\end{array}$ & $\begin{array}{l}\text { Rater } \\
\text { blinded }\end{array}$ & 45 & $\begin{array}{c}\text { Quetiapine, 37.1; } \\
\text { clozapine, } 37.4\end{array}$ & 88.9 & $\begin{array}{c}\text { Quetiapine, } \\
91(25-200) ; \\
\text { clozapine, } \\
26(12.5-50)\end{array}$ & 3 & BPRS, CGI & $\begin{array}{l}\text { BPRS: clozapine, } \\
P<0.001 \text {; quetiapine, } \\
P<0.001 \text {; CGI: } \\
\text { improved; clozapine, } \\
P<0.001 \text {; quetiapine, } \\
P<0.001\end{array}$ \\
\hline $\begin{array}{l}\text { Merims } \\
\text { et al, } \\
2006^{47}\end{array}$ & $\begin{array}{c}\text { Rater } \\
\text { blinded }\end{array}$ & 27 & NA & 59.2 & $\begin{array}{c}\text { Quetiapine, 90.9; } \\
\text { clozapine, } 13.1\end{array}$ & 5.5 & $\begin{array}{l}\text { NPI-Total, } \\
\text { CGIC }\end{array}$ & $\begin{array}{l}\text { NPI hallucinations; } \\
\text { clozapine, } P<0.002 \text {; } \\
\text { quetiapine, } P=N S \text {; } \\
\text { NPI delusions: } \\
\text { clozapine, } P<0.015 \text {; } \\
\text { quetiapine, } P=N S \text {; } \\
\text { CGIC: clozapine, } \\
P<0.001 \text {; quetiapine, } \\
P<0.001\end{array}$ \\
\hline
\end{tabular}

BPRS = Brief Psychiatric Rating Scale (range, 0-108 if using 0-6 scale or 18-126 if using 1-7 scale; each of 18 items rated from not present to extremely severe); $\mathrm{CGI}=$ Clinical Global Impression of Improvement (range, $0-7 ; 0=$ not assessed, $4=$ no change, $7=$ very much worsened); NA = not applicable; NPI-Total = Neuropsychiatric Inventory total sum of scores (range, $0-120$; subscales for frequency [4-point scale; $4=$ very frequent] and severity [3-point scale; $3=$ severe]; $\mathrm{CGIC}=$ Clinical Global Impression of Change. 
Morgante et $\mathrm{al}^{46}$ reported on a randomized, open-label, rater-blinded, comparison trial of quetiapine and clozapine, using the BPRS and CGI as the primary outcome measures; 45 patients were included in this study, 40 of whom completed the study (completion rate, $88.9 \%)$. Three $(13.0 \%)$ of 23 patients in the clozapine group and $1(4.5 \%)$ of 22 patients in the quetiapine group did not complete the study. Reasons for discontinuation included dizziness, severe hypotension, and oversedation in the clozapine group and confusion in the quetiapine group ( 1 patient each). The mean doses were $26 \mathrm{mg} / \mathrm{d}$ for clozapine and $91 \mathrm{mg} / \mathrm{d}$ for quetiapine. Improvement based on CGI-SI scores compared with baseline were reported for both groups after 3 months of treatment (both, $P<0.001$ ). Individual changes in BPRS scores were significant for each treatment group: clozapine changed from 15.5 at baseline to 8.4 at end point $(P<0.001)$; quetiapine changed from 16.4 at baseline to 8.4 at end point $(P<0.001)$. However, Morgante et $\mathrm{al}^{46}$ reported "no statistical difference" in BPRS scores between the clozapine and quetiapine groups ( $P$ value not reported).

In 2006, Merims et $\mathrm{al}^{47}$ conducted a randomized, rater-blinded, comparative trial using the Clinical Global Impression of Change (CGIC), hallucination frequency and severity, and delusion frequency and severity as outcome measures. The mean clozapine dose was $13 \mathrm{mg} / \mathrm{d}$, and the mean quetiapine dose was 90 $\mathrm{mg} / \mathrm{d}$. The study lasted 5.5 months, and the completion rate was poor $(59 \%)$. Reasons for withdrawal in the quetiapine group were lack of efficacy (4 patients) and sleepiness (2); reasons for withdrawal in the clozapine group were decreased leukocytes (3) and difficulty keeping up with the weekly blood counts (1). At the end of the study period, improvement in CGIC scores over baseline were reported for both clozapine and quetiapine (both, $P<0.001$ ), but no significant difference was found between the clozapine and quetiapine groups (no data were reported). A greater reduction in hallucination frequency over baseline was found with clozapine $(P<0.01)$ than with quetiapine $(P$ value not reported). After 5 months, improvement in delusions over baseline was reported for clozapine $(P<0.015)$ but not for quetiapine ( $P$ value not reported). Neither medication improved the severity of hallucinations or delusions.

\section{Noncomparative Trial of Clozapine and Quetiapine Interventions}

Goetz et $\mathrm{al}^{48}$ described the effects of antipsychotic intervention on hallucination and psychosis in patients with PD over the long term (12 months). Two groups were compared: one with pharmacologic intervention (31 patients) and one without pharmacologic intervention ( 33 patients). Both groups were further classified based on reductions in PD-related medications: those receiving antipsychotic medications (12 patients), those receiving antipsychotic medications and reductions in PD-related medications (19 patients), those receiving no antipsychotic treatment but reductions in PD-related medications (13 patients), and those receiving nonpharmacologic interventions only (eg, education, counseling, keeping lights on at night, sleep hygiene recommendations) (20 patients). Clozapine therapy was started in 8 patients, and quetiapine therapy was started in 23 patients. Three patients in the quetiapine group had transient switches to aripiprazole but were restarted on quetiapine due to sedation from aripiprazole. The mean doses were $39 \mathrm{mg} / \mathrm{d}$ for clozapine and $46.7 \mathrm{mg} / \mathrm{d}$ for quetiapine. The primary end point was the time from the first thought disorder item on the UPDRS for hallucinations to increase from 2 to $>2$. More than half of the patients $(59.4 \% ; 38 / 64)$ experienced the end point. The mean follow-up was 31 months (range, 2-110 months). Worsening of hallucinations was experienced by fewer of the patients who received antipsychotic medications $(25.8 \% ; 8 / 31)$ than by those who did not receive antipsychotic medications $(90.9 \% ; 30 / 33)$. The investigators calculated a hazard ratio (HR) to assess the potential reduction in progression with treatment $(\mathrm{HR}=0.156 ; 95 \% \mathrm{CI}, 0.067$ $0.363 ; P<0.001)$. The investigators also reported a longer time to worsening of hallucinations with antipsychotic medication use (39 vs 12 months) in those without antipsychotic treatment ( $P$ value not reported). Only the group with reduction in PD-related medications experienced worsening of motor function over baseline, as measured on the UPDRS-Motor subscale $(P=0.031)$. No significant changes in UPDRS-Motor scores were noted in the antipsychotic medication group.

\section{DISCUSSION \\ Study Designs}

Since guidelines were published in 2006, numerous case reports, case series, retrospective, and prospective observational studies have been published. However, only 3 RCTs have appeared in the literature. ${ }^{41,44,45}$ Two of the RCTs were conducted in patients with PD and dementia or DLB. ${ }^{44,45}$ Neither of those studies reported a difference in BPRS scores between the groups, but improvement based on CGI scores was 
Eng, Marty L. and Welty, Timothy E. (1999) Management of Hallucinations and Psychosis in Parkinson's Disease.

Am J Geriat Pharm. 8(4), 316-330. PMID: 20869621. Publisher's official version: <http://dx.doi.org/10.1016/j.amjopharm.2010.08.004> .

Open Access version: http://kuscholarworks.ku.edu/dspace/.

reported in both studies. The most common reasons for not completing the study conducted by Rabey et $\mathrm{al}^{44}$ included lack of response and adverse effects. However, the differences between the groups were not statistically significant. A plausible reason for the lack of treatment difference was the milder symptoms seen at baseline.

In the study by Kurlan et al, ${ }^{45}$ dropouts were reported more frequently in the placebo group (35\%) than in the quetiapine group (15\%). The overall high dropout rate and high placebo response could have diluted the power of the study. Interestingly, the magnitude of change in the BPRS was 8.2 points, which was not statistically different from that of the PSYCLOPS (Psychosis and Clozapine in Parkinson's Disease) study. ${ }^{22}$ The third RCT, by Ondo et al, ${ }^{41}$ had a strong study design but reported a lack of treatment difference. The milder baseline BPRS scores may explain this finding. Additional studies in larger cohorts are needed.

\section{Clozapine Studies}

The study by Gomide et $\mathrm{al}^{38}$ provided information about a Brazilian cohort. This may not be generalizable to other populations. The lack of standardized outcomes and the descriptive nature of the study make it difficult to draw conclusions regarding the effectiveness of clozapine. Pollak et $\mathrm{al}^{36}$ added more long-term perspective on the use of clozapine. The high relapse rate in those who discontinued treatment suggests that psychotic symptoms may need to be treated over longer periods. This needs to be confirmed in future studies. The study by Fernandez et $\mathrm{al}^{37}$ described 5 -year outcomes and suggested that $\sim 33 \%$ of patients with PD and psychosis would be admitted to a nursing home and $44 \%$ would die over those 5 years.

This brings up the important question of outcomes. To date, neuropsychiatric scales such as the BPRS serve as the main treatment outcome. This therapeutic goal is largely symptomatic. Studies should be undertaken to explore outcomes such as caregiver stress, function, and quality of life.

\section{Quetiapine Studies}

Seven studies were examined. ${ }^{39-45}$ Four studies ${ }^{39-41,44}$ specifically addressed quetiapine use in PD psychosis, and 3 studies ${ }^{42,43,45}$ examined potential differences in response between PD patients with and without dementia. Two studies ${ }^{39,40}$ reported a favorable benefit and 2 studies ${ }^{41,44}$ did not. Juncos et $\mathrm{al}^{40}$ and Mancini et al extended the current data to suggest that quetiap- ine could be beneficial and well tolerated over the long term. However, it should be kept in mind that neither study was controlled. Results of the Juncos study supported the role of quetiapine in patients in whom previous treatment with other antipsychotics (eg, clozapine, olanzapine, risperidone) failed. Given the recommendations in the AAN guideline to use clozapine or quetiapine but not olanzapine, this appeared to suggest that quetiapine would be a reasonable alternative for those patients and others who did not benefit from treatment or do not wish to undergo the extensive testing and monitoring needed with clozapine. Results of the study by Mancini et al supported a long-term role for quetiapine without motor worsening in patients with PD and psychosis.

The RCT conducted by Rabey et $\mathrm{al}^{44}$ reported a lack of effectiveness with quetiapine. Possible explanations include the loss of power from dropouts and the high prevalence of dementia. The effects of dementia on drug effectiveness are not clear (discussed later). Ondo et $\mathrm{al}^{41}$ also failed to find effectiveness of quetiapine in their RCT. However, the BPRS scores at baseline in that study suggested milder symptoms initially.

Prohorov et $\mathrm{al}^{42}$ were the first group to compare PD patients with and without dementia and the effects of dementia on treatment response in psychosis. Results of their 6-month study were conflicting. No substantial difference in BPRS scores was found; however, based on CGI scores, improvement was reported more frequently in patients with dementia than in those without dementia. Unfortunately, no statistical analysis was conducted on CGI scores; therefore, the significance of this difference is unknown.

Klein et $\mathrm{al}^{43}$ extended the data from the Prohorov study ${ }^{42}$ to 24 months. No significant difference was seen in patients with dementia, and those without dementia improved. Again, no statistical analysis was reported.

Finally, Kurlan et $\mathrm{al}^{45}$ investigated a mixed cohort of patients with DLB, PD with dementia, and Alzheimer's disease with parkinsonian features. Over 2.5 months, no significant differences were observed in this cohort. Although the overall completion rate was poor, patients in the quetiapine group were more likely than those in the placebo group to complete the study ( $85 \%$ vs $65 \%$, respectively). It is likely that the poor completion rate diluted the study's statistical power. Currently, it is unclear whether patients with dementia respond differently from those without dementia. Further research is needed to investigate this issue. A study design barrier may explain the high dropout rate in this population 
with advanced disease.

\section{Comparative Trials}

Two comparative trials ${ }^{46,47}$ were reviewed. Both studies confirmed that clozapine and quetiapine were not significantly different in terms of effectiveness when used to manage hallucinations and psychosis in patients with PD. Differences in tolerability were less clear given the small sample sizes. Both studies were limited by their open-label design and lack of a placebo group. However, given the acceptance of clozapine as "probably effective," 20 it is reasonable to conduct future studies using clozapine as the active comparator instead of a placebo.

\section{Other Atypical Antipsychotics}

Although studies of aripiprazole, olanzapine, risperidone, and ziprasidone have been published, all were small case series. Miyasaki et al ${ }^{20}$ concluded that olanzapine should always be avoided in patients with PD. Since publication of the 2006 AAN guideline, few data have been published to suggest any changes in practice. Nevertheless, the recent literature adds to the understanding of the advantages and disadvantages of using clozapine or quetiapine. Fernandez et $\mathrm{al}^{37}$ appeared to be the first group to report on clinical outcomes of 5 -year mortality with clozapine in PD psychosis.

\section{CONCLUSIONS}

Published data regarding the treatment of psychosis and hallucinosis in patients with PD are scant and limited by the study designs. Based on the few trials that have been published, both clozapine and quetiapine are reasonable pharmacotherapeutic options for moderate to severe psychosis in patients with PD. There is not enough evidence for or against other atypical antipsychotics to draw any conclusions regarding their use in these patients. Currently, it is unclear whether patients with PD and dementia respond differently to quetiapine therapy than patients without dementia. Future research should continue to explore the presentation of psychosis in patients with PD and their treatment response patterns.

\section{ACKNOWLEDGMENTS}

Dr. Eng, the primary author, was responsible for the study design, literature search and article retrieval, literature analysis, and drafting of the manuscript. Dr. Welty assisted with the development, editing, and review of the manuscript. The authors have indicated that they have no conflicts of interest with regard to the content of this article.

\section{REFERENCES}

1. Holroyd S, Currie L, Wooten GF. Prospective study of hallucinations and delusions in Parkinson's disease. $J$ Neurol Neurosurg Psychiatry. 2001;70:734-738.

2. Aarsland D, Larsen JP, Cummins JL, Laake K. Prevalence and clinical correlates of psychotic symptoms in Parkinson disease: A community-based study. Arch Neurol. 1999;56:595-601.

3. Meral H, Aydemir T, Ozer F, et al. Relationship between visual hallucinations and REM sleep behavior disorder in patients with Parkinson's disease. Clin Neurol Neurosurg. 2007;109:862-867.

4. Papapetropoulos S, Katzen H, Schrag A, et al. A questionnaire-based (UM-PDHQ) study of hallucinations in Parkinson's disease. BMC Neurol. 2008;8:21.

5. Holt RJ. Estimate of point prevalence of Parkinson's disease induced psychosis in the United States. Mov Disord. 2008;23:1788-1789.

6. Weintraub D, Morales KH, Duda JE, et al. Frequency and correlates of co-morbid psychosis and depression in Parkinson's disease. Parkinsonism Relat Disord. 2006;12:427-431.

7. Papapetropoulos S, Mash DC. Psychotic symptoms in Parkinson's disease. From description to etiology. $J \mathrm{Neu}^{-}$ rol. 2005;252:753-764.

8. Papapetropoulos S, Argyriou AA, Ellul J. Factors associated with drug-induced visual hallucinations in Parkinson's disease. J Neurol. 2005;252:1223-1228.

9. Giladi N, Treves TA, Paleacu D, et al. Risk factors for dementia, depression and psychosis in long-standing Parkinson's disease. J Neural Transm. 2000;107:59-71.

10. Ecker D, Unrath A, Kassubek J, Sabolek M. Dopamine agonists and their risk to induce psychotic episodes in Parkinson's disease: A case-control study. BMC Neurol. 2009;9:23.

11. Reijnders JS, Ehrt U, Lousberg R, et al. The association between motor subtypes and psychopathology in Parkinson's disease. Parkinsonism Relat Disord. 2009;15:379-382.

12. Stavitsky K, McNamara P, Durso R, et al. Hallucinations, dreaming, and frequent dozing in Parkinson disease: Impact of right-hemisphere neural networks. Cogn Behav Neurol. 2008;21:143-149.

13. Biglan KM, Holloway RG Jr, McDermott MP, Richard IH, for the Parkinson Study Group CALM-PD Investigators. Risk factors for somnolence, edema, and hallucinations in early Parkinson disease. Neurology. 2007;69:187-195.

14. Ravina B, Marder K, Fernandez HH, et al. Diagnostic 
Eng, Marty L. and Welty, Timothy E. (1999) Management of Hallucinations and Psychosis in Parkinson's Disease.

Am J Geriat Pharm. 8(4), 316-330. PMID: 20869621. Publisher's official version: <http://dx.doi.org/10.1016/j.amjopharm.2010.08.004> . Open Access version: http://kuscholarworks.ku.edu/dspace/.

The American Journal of Geriatric Pharmacotherapy $\quad$ M.L. Eng and T.E. Welty

criteria for psychosis in Parkinson's disease: Report of an NINDS, NIMH work group. Mov Disord. 2007;22:1061-1068.

15. Goetz CG, Leuragans S, Papert EJ, et al. Prospective longitudinal assessment of hallucinations in Parkinson's disease. Neurology. 2001;57:2078-2082.

16. de Maindreville AD, Fenelon G, Mahieux F. Hallucinations in Parkinson's disease: A follow-up study. Mov Disord. $2005 ; 20: 212-217$.

17. Goetz CG, Stebbins GT. Risk factors for nursing home placement in advanced Parkinson's disease. Neurology. $1993 ; 43: 2227-2229$.

18. Goetz CG, Stebbins GT. Mortality and hallucinations in nursing home patients with advanced Parkinson's disease. Neurology. 1995;45:669-771.

19. Aarsland D, Larsen JP, Cummings JL. Mortality and hallucinations in Parkinson's disease: A four-year longitudinal study. J Neuropsychiatry Clin Neurosci. 1997;9:642.

20. Miyasaki JM, Shannon K, Voon V, et al, for the Quality Standards Subcommittee of the American Academy of Neurology. Practice Parameter: Evaluation and treatment of depression, psychosis, and dementia in Parkinson disease (an evidence-based review): Report of the Quality Standards Subcommittee of the American Academy of Neurology. Neurology. 2006;66:996-1002.

21. American Academy of Neurology. AAN guideline development process. http://www.aan.com/go/practice/ guidelines/development. Accessed August 9, 2010.

22. Parkinson Study Group. Low-dose clozapine for the treatment of drug-induced psychosis in Parkison's disease. $N$ Engl J Med. 1999;340:757-763.

23. Morgante L, Epifanio A, Spina E, et al. Quetiapine versus clozapine: A preliminary report of comparative effects on dopaminergic psychosis in patients with Parkinson's disease. Neurol Sci. 2002;23:S89-S90.

24. Breier A, Sutton VK, Feldman PD, et al. Olanzapine in the treatment of dopamimetic-induced psychosis in patients with Parkinson's disease. Biol Psychiatry. 2002;52:438-445.

25. Ondo W, Levy JK, Vuong KD, et al. Olanzapine treatment for dopaminergic-induced hallucinations. Mov Disord. 2002;17:1031-1035.

26. Ballard CG, Margallo-Lana M, Fossey J, et al. A 1-year follow-up study of behavioral and psychological symptoms in dementia among people in care environments. $J$ Clin Psychiatry. 2001;62:631-636.

27. Selbaek G, Kirkevold O, Engecal K. The course of psychiatric and behavioral symptoms and the use of psychotropic medications in patients with dementia in Norwegian nursing homes-a 12-month follow-up. Am J Geriatr Psychiatry. 2008;16:528-536.
28. Overall JE, Gorham DR. The Brief Psychiatric Rating Scale. Psychol Rep. 1962;10:799-812.

29. Berk M, Ng F, Dodd S, et al. The validity of the Clinicians Global Impression severity and improvement scales as measures for clinical effectiveness suitable for routine clinical use. J Eval Clin Pract. 2008;14:979-983.

30. Hoehn MM, Yahr MD. Parkinsonism: Onset, progression, mortality. Neurology. 1967;17:427-442.

31. Folstein M, Robins L, Helzer J. The mini-mental state examination. Arch Gen Psychiatry. 1983;40:812.

32. Cummings JL, Mega M, Gray K, et al. The neuropsychiatric inventory: Comprehensive assessment of psychopathology in dementia. Neurology. 1994;44:2308-2314.

33. Freidberg G, Zoldan J, Weizman A, et al. Parkinson's Psychosis Rating Scale: A practical instrument for grading psychosis in Parkinson's disease. Clin Neurpharmacol. 1998;2:280-284.

34. Leucht S, Kane JM, Kissling W, et al. What does the Positive and Negative Symptoms Scale mean? Schizo Res. 2005;79:231-238.

35. Goetz CG, Tilley BC, Shaftman SR, et al. Movement Disorders Society-Sponsored revision of Unified Parkinson's Disease Rating Scale: Scale presentation and clinimetric testing results. Mov Disord. 2008;23:2129-2170.

36. Pollak P, Tison F, Rascol O, et al. Clozapine in drug induced psychosis in Parkinson's disease: A randomised, placebo controlled study with open follow up. J Neurol Neurosurg Psychiatry. 2004;75:689-695.

37. Fernandez HH, Donnelly EM, Friedman JH. Long-term outcome of clozapine use for psychosis in parkinsonian patients. Mov Disord. 2004;19:831-833.

38. Gomide L, Kummer A, Cardoso F, Teixeira AL. Use of clozapine in Brazilian patients with Parkinson's disease. Arq Neuropsiquiatr. 2008;66:611-614.

39. Mancini F, Tassorelli C, Martignoni E, et al. Long-term evaluation of the effect of quetiapine on hallucinations, delusions and motor function in advanced Parkinson disease. Clin Neuropharmacol. 2004;27:33-37.

40. Juncos JL, Roberts VJ, Evatt ML, et al. Quetiapine improves psychotic symptoms and cognition in Parkinson's disease. Mov Disord. 2004;19:29-35.

41. Ondo WG, Tintner R, Voung KD, et al. Double-blind, placebo-controlled, unforced titration parallel trial of quetiapine for dopaminergic-induced hallucinations in Parkinson's disease. Mov Disord. 2005;20:958-963.

42. Prohorov T, Klein C, Miniovitz A, et al. The effect of quetiapine in psychotic Parkinsonian patients with and without dementia. An open-labeled study utilizing a structured interview. J Neurol. 2006;253:171-175.

43. Klein C, Prokhorov T, Miniovich A, et al. Long-term 
Eng, Marty L. and Welty, Timothy E. (1999) Management of Hallucinations and Psychosis in Parkinson's Disease.

Am J Geriat Pharm. 8(4), 316-330. PMID: 20869621. Publisher's official version: <http://dx.doi.org/10.1016/j.amjopharm.2010.08.004> . Open Access version: http://kuscholarworks.ku.edu/dspace/.

follow-up (24 months) of quetiapine treatment in druginduced Parkinson disease psychosis. Clin Neuropharmacol. 2006;29:215-219.

44. Rabey JM, Prokhorov T, Miniovitz A, et al. Effect of quetiapine in psychotic Parkinson's disease patients: A double-blind labeled study of 3 months' duration. Mov Disord. 2007;22:313-318.

45. Kurlan R, Cummings J, Raman R, Thal L, for the Alzheimer's Disease Cooperative Study Group. Quetiapine for agitation or psychosis in patients with dementia and parkinsonism. Neurology. 2007;68:1356-1363.

46. Morgante L, Epifanio A, Spina E, et al. Quetiapine and clozapine in parkinsonian patients with dopaminergic psychosis [published correction appears in Clin Neuropharmacol. 2004;27:256]. Clin Neuropharmacol. 2004;27:153-156.

47. Merims D, Balas M, Peretz C, et al. Rater-blinded, prospective comparison: Quetiapine versus clozapine for Parkinson's disease psychosis. Clin Neuropharmacol. 2006;29:331-337.

48. Goetz CG, Fan W, Leurgans S. Antipsychotic medication treatment for mild hallucinations in Parkinson's disease: Positive impact on long-term worsening. Mov Disord. 2008;23:1541-1545.

Address correspondence to: Marty L. Eng, PharmD, Clinical Assistant Professor, Department of Pharmacy Practice, University of Kansas School of Pharmacy, 3901 Rainbow Boulevard, MS 4047, Room B440, Kansas City, KS 66160. E-mail: meng@kumc.edu 